\title{
HISTORIOGRAFIA BRASILEIRA E TEORIA DA FRONTEIRA NATURAL.
}

\author{
ALDO JANOTTI \\ do Departamento de História da Faculdade de Filo- \\ sofia, Letras e Ciências Humanas da Universidade de \\ São Paulo.
}

\begin{abstract}
"Laissons à l'astuce des uns, à la candeur des autres, la "frontière naturelle": il n'y a de frontières qu'humaines. Elles sont "justes" ou "injustes", mais ce n'est pas "la nature" qui dicte l'équité ou conseille la violence" (Albert Demangeon, Lucien Febvre, Le Rhin-Problèmes d'Histoire et d'Economie, $\mathrm{X}$ ).
\end{abstract}

No seu estudo $O$ Desenvolvimento da Filosofia no Brasil no século XIX e a Evolucão histórica nacional. João Cruz Costa tem oportunidade de escrever o seguinte, referindo-se ao comportamento que devemos tomar face às idéias estrangeiras, mormente às idéias européas, quando, poderosamente carregadas de energia influenciadora, chegaram e continuam chegando ao Brasil:

"O pensamento é sempre produto da atividade de um povo e, assim, é para a nossa história, nas suas relações com a história universal, que devemos voltar-nos para apreender a nossa própria significação, o sentido do nosso espirito, a fim de melhor compreendermos os matizes das transformações de idéias que vieram exercer influência no nosso meio. Muita idéia mudou e muita teoria nascida do outro lado do Atlântico tomou aqui expressões que não parecem perfeitamente condizentes com as suas "premissas" originais. E que há um estilo próprio aos diferentes meios, estilo esse condicionado pelas vicissitudes históricas dos povos, que determina ou que influi na transformação dos sistemas que a inteligência constroi para explicar a vida" (1).

(1). - São Paulo, 1950, p. 12. 
O pensamento, magistralmente expresso pelo ilustre ex-professor de Filosofia da Universidade de São Paulo, não é, porem, original . Muitos intelectuais, preocupados com as vicissitudes das idéias estrangeiras no Brasil, têm-se manifestado mais ou menos da mesma forma. E assim, por exemplo, que Sílvio Romero, no século passado, em obra comemorativa do centenário da morte do marquês de Pombal - elaborada por vários autores, estrangeiros e brasileiros - e inexplicavelmente publicada três anos após a data a que se propunha comemorar, assim se manifestava:

\begin{abstract}
"Alguns sectários da simetria na história explicam o espetáculo do desenvolvimento americano como uma espécie de reprodução do que se tem dado na Europa a datar da Idade Média. Levados por este pensamento dirigente, dividem os povos europeus em latinos e germânicos, católicos e protestantes, e os da América em duas iguais categorias; e daí deduzem uma que filosofia da história"; e acrescentava, mais adiante: "Tal teoria tem, alem do mais, o defeito de considerar a civilização americana como um todo emigrado, um movel de luxo transferido no convés dos navios da Europa para este continente; e passa a esponja sobre os elementos autônomos fornecidos pelas raças indigenas, pela ação do meio físico e pelos povos africanos incorporados a nós" (2).
\end{abstract}

Nem sempre, no entanto, os indivíduos que se têm preocupado com a interpretação das coisas brasileiras souberam compreender a legitimidade e a significação das proposições enquadradas no pensamento dos dois intelectuais, um moderno e outro antigo, que acabamos de citar. Teima-se, ainda, em explicar certas particularidades do nosso passado, mediante a aplicação pura e simples de teorias alienígenas, sem se cuidar que, dificilmente, as mesmas encontrariam eco e possibilidade de vigência num país de vicissitudes históricas tão diversas das da sua terra de origem. Tal é o caso, por exemplo, da teoria da fronteira natural, tomada pela quase unanimidade dos nossos historiadores como idéia determinante da política de D. João VI na região do Prata, e que tantas consequências iria projetar na evolução histórica de alguns paises do continente sul-americano, inclusive do Brasil.

Realmente. Em 1816 D. João VI ordenava a invasão do Uruguai, uma das três regiōes que formavam o antigo Vice-Reino do Prata para, consequentemente, incorpora-lo ao Brasil em 1821 sob o nome

(2). - O Marquês de Pombal, Lisboa, Imprensa Nacional, 1885, $2 \mathrm{a}$. parte, p. 36 . 
de Província da Cisplatina. Por que assim procedeu o monarca português, dando uma demonstração de belicosidade não condizente com o seu por vezes demasiadamente pacífico carater e, ao mesmo tempo, capaz de atrair a antipatia, quando não mesmo a represália das potências européias, surpreendidas e inconformadas com semelhante atitude? Caso não se caracterizasse a historiografia brasileira pela quase ausência da controvérsia na compreensão dos fatos da nossa história, controvérsia esta que é, antes de mais nada, um atestado de riqueza historiográfica, não teríamos o dissabor de observar a pobreza da mesma quando, através de uma cômoda maioria, se procura solucionar tal questão. Escolhe-se uma teoria, sabidamente originada na Europa, e "muito em voga na época", a da fronteira natural, e um autor, como que repetindo o outro, vê nesta teoria a "causa determinante" da intervenção de D. João VI no Prata, sem se preocupar se a referida teoria poderia ser aplicada na história do Brasil - visto que o ambiente geo-histórico brasileiro era, como é, completamente diferente do europeu - e, o que é pior, se ela chegou mesmo a ser aplicada na própria história da Europa...

Vejamos alguns dos nossos historiadores, na desconfortante maioria das suas opiniões. E assim que Oliveira Lima, muito embora reconhecesse

"não poder o Brasil, por reconhecidamente ordeiro, suportar sem perigo próprio um foco de perturbação tão perto das suas comunidades pacíficas e laboriosas", afirmava que a "ocupação tinha, porem, por motivos verdadeiros facultar ao Brasil sua fronteira natural no sul" (3).

\section{Tasso Fragoso dizia:}

"A monarquia portuguesa, persistente em seu projeto de conquistar as regiões do sul, para possuir desse lado, como limite do Brasil, a borda do Prata, resolve invadir pela segunda vez o Estado Oriental, com um exército composto em grande parte de tropas aguerridas, mandadas vir especialmente da metrópole européia" (4).

(3). - Dom João VI no Brasil, Rio de Janeiro, Livraria José Olimpio Editora, 1945, II, 2a. edição, p. 625.

(4) . - A Batalha do Passo do Rosário, Rio de Janeiro, Imprensa Militar, 1922, p. 110 . 
Fernando Nobre - autor não da opinião, como erroneamente acredita Souza Docca (5), de que foi a campanha

"para a incorporação da Banda Oriental ao Brasil, obra maldita do despotismo, baseada no materialismo, negação deploravel de todos os princípios do direito e da moral, negação absoluta do homem, criado à imagem do seu Deus",

pois que ela é, na realidade, da autoria de L. F. da Veiga (6), por sua vez tambem asseverava:

"E as ambições que D. João VI nutria de dilatar os seus limites, ao menos, até o Prata, sobrepassavam todas as considerações" (7).

Calógeras referia-se aos inúmeros pretextos para a intervenção, mas ressaltava que a

"idéia diretora fundamental era a conquista da fronteira natural" (8),

orientando D. João VI

"sua rota pela política tradicional de Portugal, no sentido de traçar a fronteira natural do Brasil pelo rio Paraná e pelo rio da Prata",

provando com isso, mais uma vez, não haver entendido a posição da Inglaterra, contrária à qualquer intervenção (9).

Souza Docca foi dos autores que mais se preocuparam com a intervenção de D. João VI no Prata. Julgando que o assunto tem sido tratado pela rama ou mencionado em simples referências pela maioria dos historiadores brasileiros (10), cita três ordens de causas da refe-

(5). - O Brasil no Prata; 1815-1828, Porto Alegre, separata da "Revista do Instituto Histórico e Geográfico do Rio Grande do Sul", 1931, ano XI, p. 14.

(6) . - Apud Fernando Nobre, As Fronteiras do Sul, São Paulo, Monteiro Lobato \& Cia., 1922, p. 304.

(7). - Op. cit., p. 277 .

(8). - Politica Exterior do Império, Rio de Janeiro, Imprensa Nacional, 1927, 1, p. 434 .

(9). - Formação Histórica do Brasil, São Paulo, Companhia Editora Nacional, 1945, 4a. edição, p. 88.

(10). - Op. cit., p. 3 . 
rida intervenção: causas predisponentes (monarquismo dos platinos, idéias de Artigas sobre o Rio Grande do Sul, turbulências de Artigas, barbarismo dos caudilhos e caudilhetes); causas eficientes ou accessórias (contra a autoridade de Artigas, preferência dos uruguaios pelo domínio brasileiro, agressões de Artigas); e causa final, a mais decisiva, portanto (limite pelo rio da Prata) (11). Prova de que não está quase que isolado sob o ponto de vista com que encarava a política luso-brasileira da ocupação da Banda Oriental, como enganosamente acreditava (12), tambem ele afirmava - só que justificava muito mais enfaticamente do que os outros - que o

“objetivo da invasão da Banda Oriental, em 1816, era, como já ficou dito: fixar na margem esquerda do Prata nossos limites meridionais" (13),

e isto porque, essa

"região, como ninguem ignora, está ligada ao Brasil sem nenhum dos acidentes geográficos que, em regra, marcam as raias dos paises confinantes e sim, por um território contínuo, motivo porque nenhuma diferença se nota ao transpor a atual fronteira política entre o Brasil e o Uruguai, determinada, em grande extensão, por uma linha seca" (14).

Eis aí o motivo determinante por excelência ou a causa final da invasão. Não tendo o Uruguai fronteiras naturais que o separassem do Brasil, não deveria ele se constituir num Estado e sim no extremo meridional de um outro Estado, no caso o Brasil, cuja fronteira, então, deveria extender-se até o seu limite natural, isto é, o rio da Prata.

Não estava, portanto, Souza Docca "quase que isolado" na apreciação das causas da intervenção de D. João VI no Prata. E nem estaria, pois o refrão monótono do "fronteirismo natural" continuaria depois dele. E assim que Lima Figueiredo, sem levar em conta quaisquer outras razões, afirmava secamente:

"D. João, aproveitando a confusão reinante, resolveu incorporar ao Brasil a Banda Oriental com o nome de Provincia Cis-

(11). - Idem, p. 3-4

(12). - Idem, p. 7 .

(13). - Idem, p. 13-14.

(14). - Idem, p. 13. 
platina, satisfazendo assim um doce anhelo dos seus antepassados levar os limites da colônia até ao Prata" (15).

Da mesma opinião era Macedo Soares quando dizia que os

"reis da casa de Bragança alimentaram sempre o ideal de extender a fronteira da colonia lusitana até a margem esquerda do Rio do Prata" (16).

E tambem Renato Mendonça, quando se referia à secular aspiração portuguesa da margem esquerda do rio da Prata (17).

Os compêndios escolares postos à disposição dos nossos estudantes secundários, geralmente não elaborados por autênticas autoridades da História, fazem coro - e poderia ser diferente? - da opinião dos historiadores acima citados. Jônatas Serrano observava que era

"um velho sonho da metrópole extender os limites do Brasil no sul até ao Prata" (18).

Joaquim Silva falava que

"Portugal pretendia extender ao Prata as divisas brasileiras" (19).

Vicente Tapajóz escrevia:

"Sempre fora desejo de Portugal colocar como limite meridional de suas colônias americanas o rio da Prata" (20).

E por aí a fora.

(15) - Limites do Brasil, Rio de Janeiro, Casa Editora Henrique Velho, 1936, p. 194.

(16). - Fronteiras do Brasil no regime colonial, Rio de Janeiro, Livraria José Olimpio, 1939, p. 194.

(17). - História da Política Exterior do Brasil, México, Instituto Panamericano de Geografia y Historia, 1945, p. 92. p. 300 .

(18). - História do Brasil, Rio de Janeiro, F. Briguiet \& Cia., 1931,

(19). - História do Brasil, São Paulo, Companhia Editora Nacional, 1945, 14a. edição. p. 246.

(20). - História do Brasil, São Paulo, Companhia Editora Nacional, 1946, 2a. edição, p. 242. 
E bem verdade que se poderia fazer uma objeção. Tanto os historiadores quanto os compendiadores arrolados, unânimes na aceitação da fronteira natural como "causa" da invasão do Uruguai, não são autores já antigos e, por consequência, representantes de uma interpretação historiográfica ultrapassada? Afinal, um bom espaço de tempo se passou de Oliveira Lima (a primeira edição do seu livro é de 1908), a Vicente Tapajóz, e deste até os dias que correm! Não seria hoje diferente, num claro reflexo de modernização ou de progresso do pensamento histórico brasileiro, a opinião de historiadores mais recentes? Infelizmente, a resposta é não. Ainda se continua repisando e repicando o mesmo tema, fronteira natural. Tal é a fixação à idéia da fronteira natural que, há questão de meses, um historiador categoricamente afirmava:

"Com a fundação da Colônia do Sacramento em 1680, os portugueses criaram a "ilusão do Prata", para utilizar conceito de Euclides da Cunha; e essa "ilusão do Prata" foi a fôrça motivadora da presença de Portugal no estuário platino e na campina uruguaia" (21).

Dessa forma, é indiscutivel que, pelo menos historiograficamente, D. João VI invadiu o Uruguai e o incorporou ao Brasil sob o nome de Província da Cisplatina levado por um determinismo, o determinismo geográfico da fronteira natural. Mas... entre o que se escreveu e se escreve a respeito de um fato e o que de fato aconteceu, pode haver uma grande, uma enorme distância. Distância mais do que suficiente para que a História recuse endosso à Historiografia.

A teoria da fronteira natural tem sua origem na Europa. Já era uma idéia familiar aos antigos, tomou consistência no século XVI com o grande esforço cartográfico que se realizou no sentido de fixar a figura da Terra, sendo logo utilizada como apôio das cobiças políticas, manteve-se durante o chamado Antigo Regime, foi durante certo tempo invocada na Revolução Francesa, permanecendo assim, tenazmente arraigada no fundo dos espíritos (22). Nos seus fundamentos a teoria é simples: os paises, visando maior segurança, devem, prefe-

(21) . - Teixeira Soares, História da Formação das Fronteiras do Brasil, Rio de Janeiro, Biblioteca do Exército Editora, 1973, p. 15.

(22) . - Max Sorre, Les Fondements de la Géographie Humaine, Paris, Librairie Armand Colin, 1948, II, p. 121. 
rentemente aos políticos, levar seus limites até fronteiras naturais, como por exemplo, o mar, o rio, a montanha. Envolve, portanto, tal teoria, preocupação nitidamente defensiva, estreitamente vinculada aos acidentes da natureza, justificando inclusive o caso de um esforço ofensivo que, com a mesma finalidade defensiva, procure levar os limites de um determinado país até os referidos acidentes naturais.

Eis a teoria da fronteira natural, levemente esboçada na sua história e no seu conteudo, que nossos historiadores, na sua maioria, importaram da Europa e a tomaram como causa determinante - e não como simples pretexto justificativo, note-se - da invasão do Uruguai por D. João VI. Desses historiadores, é em Souza Docca onde temos a oportunidade de, mais nitidamente, observar a apreensão de uma teoria européia para explicar um fato da história do Brasil. Este, não só procurava compreender o imperialismo brasileiro na região do Prata como outra coisa que não foi

"senão a consequência lógica, fatal, de nossa condição de fortes, de nossa situação de ordem, de nossa firme organização política" (23),

desfilando, para tanto, com o objetivo de justifica-lo, uma série de exemplos de imperialismos praticados na época moderna por paises relativa ou absolutamente fortes os mais diversos, quer da Europa, quer da América; como tambem afirmava ser erro palmar

"o julgamento do objetivo de nossos maiores ocupando a Banda Oriental, sem se ter presente a teoria das fronteiras naturais, em voga naqueles tempos" (24),

visto que 0

"território uruguaio, segundo o conceito da época, não constituia um Estado, e, sim, o extremo, o final de um Estado" (25).

Para embasar a sua afirmação de que a causa determinante da invasão do Uruguai foi a teoria da fronteira natural, Souza Docca procurou o apôio da autoridade de Lucien Febvre, citando-o duas vezes, e da seguinte maneira:

(23). - Op. cit., p. 16 .

(24). - Idem, p. 22.

(25). - Idem, p. 23 
"Desde a mais remota antiguidade", observa Lucien Febvre, "os rios alternam com as cadeias de montanhas para fornecer aos Estados limites naturais" (26), e "Quem diz limite natural", - pondera Febvre, referindo-se ao conceito então corrente, "diz limite predestinado - ideal a conquistar e a realizar" (27).

Sendo a teoria da fronteira natural uma teoria européia, nada mais compreensivel que Souza Docca cuidasse de amparar-se na autoridade de um europeu, por sinal eminente, Lucien Febvre. Mas exatamente porque assim procedeu e da maneira como o fez, o historiador brasileiro não só cometeu um descuido, como tambem, e por consequência, acabou ficando imprudentemente desamparado...

E que, embora a teoria da fronteira natural tivesse nascido na Europa, ela nunca foi levada em conta pelos próprios europeus como fator determinante de uma política, defensiva ou ofensiva. E dentre os que se tem mais esforçado no sentido de desacredita-la, outro não foi senão o próprio Lucien Febvre. No seu famoso livro sobre a Terra e a evolução humana, o intelectual francês faz crítica, e crítica contundente, à teoria da fronteira natural e quando diz que

"Desde a mais remota antiguidade os rios alternam com as cadeias de montanhas para fornecer aos Estados fronteiras naturais" e que "Quem diz limite natural, diz limite predestinado ideal a conquistar e a realizar",

está apenas e tão somente enunciando a teoria e nunca aceitando-a coisa que Souza Docca, inadvertidamente não percebeu.

Vejamos a posição de Febvre face à fronteira natural, esboçada no capítulo do seu livro referente ao problema das fronteiras e as regiões naturais dos Estados (28). Apesar de reconhecer que subsiste em nós - incrustrada de maneira tão forte que não chegamos a experimentar sua força - uma certa concepção de "marco natural" dos grandes estados, que nos faz considerar os limites como coisas

(26). - La Terre et l'évolution humaine, p. 363, apud Souza Docca, op. cit.. p. 23 .

(27). - Idem, p. 361, ibidem, p. 23.

(28). - La Tierra y la Evolución Humana - Introducción geográfica a la História, Barcelona, Editorial Cervantes, 1925, tradução de L. Pericot Garcia, p. 393-418. 
que possuem por si mesmas um valor próprio, uma espécie de virtude mecânica e ao mesmo tempo de poder coercitivo e criador (29), afirma Febvre que para a conquista ou posse dos marcos naturais (mares, rios, montanhas, bosques), mais do que um determinismo geográfico, deve-se

"ter muito em conta, nisto como em tudo, as idéias dos homens e o fato de que certos grupos podem desejar ter como limite tal acidente físico, ou limitar, pelo contrário, seus desejos à posse de tal outro, situado mais aquem, por prudência política ou econômica" (30).

Observa que montanhas, rios, bosques são frequentemente limites naturais, na medida em que realmente são obstáculos, porem, não se deve esquecer que eles são tambem laços de união, centros de expansão e de irradiação, núcleos de atração dotados de valor próprio, que unem entre si os homens e os paises vizinhos e que, em todo caso, nunca são "limites necessários" (31). Tomando os limites naturais citados, e inclusive os desertos (32), não como acidentes em condições de separar os homens e sim, muito mais, de aproxima-los, acredita ainda Febvre que um bom número de conjuntos geográficos deixa de ser considerado como simples linhas-limites (33). De forma alguma aceita a noção de marco predestinado:

"Já nada há de "coisa feita", dada pela Natureza ao homem, imposta pela Geografia à política. Há simplesmente adaptação do homem a possibilidades, concepção muito mais satisfatória, evidentemente, e muito mais rica do que a dos "marcos naturais" (34).

(29). - Op. cit.. p. 394.

(30). - Idem, p. 400.

(31). - Idem, p. 400 .

(32). - Sobre os desertos assim se refere Febvre, op. cit., p. 403, apoiando-se em Chudeau ("L'Antropologie", Paris, 1913, t. XXIV, p. 185): "?Limite las partes más ásperas y más desoladas de los desiertos? Pero Chudeau protesta, como buen conocedor del Sahara central y occidental: "Las partes más estériles del desierto, aquellas en que sólo hai arena y piedras, los tanez-rufts, no son una barrera seria para los pueblos saharianos. Aunque forman una banda ancha por lo menos de 200 kilómetros del Tagant a Egipto, no coinciden en ninguna parte con una barrera étnica; numerosas tribus tienen pastos lo mismo al N. que al S. de estas barreras áridas".

(33). - Idem, p. 404.

(34). - Idem, p. 405. 
E encerra sua penetrante crítica à fronteira natural, afirmando que o Estado nunca surge naturalmente, mas sempre deve ser criado (35), e isto depois de encarecer que nada deve ser deduzido contra a Geografia, já que ela própria, felizmente, não mais acredita nas influências massiças e diretas dos característicos do relevo ou da hidrografia sobre os fatos complexos da vida humana (36).

Assim, procurando encontrar em Lucien Febvre um apóstolo da teoria da fronteira natural, Souza Docca que tanto carecia dele, quanto tambem carecia dela, a fim de, insistentemente, utilizar-se do fator geográfico como determinante da intervenção de D. João VI no Prata, acabou, irônica e paradoxalmente, encontrando um apóstata!

Mas um apóstata que não estava só. Outros intelectuais alem dele, e geralmente geógrafos, tambem não aceitam a teoria da fronteira natural como capaz de ter atuado decisivamente no desenvolvimento da história européia. Jacques Ancel, por exemplo, não aceita a fronteira natural como fator de separação entre os homens, fator de separação este, que é um dos elementos básicos da teoria que visava dar condições de segurança aos estados, pois

"o obstáculo de maneira alguma impede a permeabilidade da fronteira" (37).

Para ele, o que de fato separa as nações ou as populações é o "vazio de humanidade" que ergue diante delas divisões mais insuperáveis que as muralhas físicas (38). Max Sorre se refere aquilo que

(35). - Idem, p. 411

(36). - Idem, p. 408 .

(37). - Géographie des Frontières, Paris, Librairie Gallimard, 1938, p. 80 .

(38). - Idem, p. 80. Com muita oportunidade Ancel faz a respeito as seguintes observações: "Si la civilisation, selon la judicieuse définition qu'en donne Vidal de la Blache, est la lutte victorieuse de l'homme contre les ovstacles que la nature a élevés devant lui, il n'est ni une muraille ni un fossé physiques qu'il ne soit parvenu à franchir: il passe les mers, enjambe les fleuves, se faufile dans les plus âpres massifs, perce les chaînes les plus serrées. En revanche le vide, qui de tous temps a écarté les masses, reste toujours une limite répulsive, franche, irréfragable: montagnes de sables, plateaux de pierres, marais d'eau ou de tourbe, forêts vierges de l'Equateur ou du septentrion, toundras gelées ou glaces polaires, jamais l'homme, même civilisé, n'est parvenu à vaincre ces vacuités. Des exploits individuels ont arraché les secrets de ces zones hostiles, la colonisation a stoppé devant l'enemi du genre humain, le vide. La carte présente des obstacles naturels, mais l'homme saute par-dessus; elle ne fait nulle place aux vides. Bref, la nature ne crée une frontière que quand elle ordonne une halte à l'homme". (Op. cit., p. 80-1); "Ce n'est guère la nature qui dresse devant l'humanité d'infranchissables barrières: ni les étendues 
chama a "ilusão das fronteiras naturais" (39): a necessidade de uma coincidência entre a fronteira política e os acidentes físicos oferece grande repouso para os espíritos ávidos de clareza e simplicidade; preocupações de segurança erigem a montanha ou o grande rio como acidentes de defesa eficazes para um Estado viver tranquilamente; e, insensivelmente, se resvala para uma concepção teológica que apresenta os quadros físicos como que preparados pela Natureza para o desenvolvimento dos estados, de maneira que o aumento territorial destes não passa da realização de uma harmonia pré-estabelecida (40). Todavia, Sorre tambem não acredita na ilusão, na ilusão das fronteiras naturais. As cadeias de montanhas como os grandes rios não só não possuem virtudes protetoras para a segurança dos estados, como não barram as populações; simples consulta a um Atlas histórico é suficiente para nos mostrar que os estados não tendem a um movimento necessário e contínuo visando a realização de uma forma pré-determinada; e, finalmente, as fronteiras naturais apenas tem o valor da comodidade quando escolhidas para separar regiōes quase que vazias de população, caso, por exemplo, do rio Grande entre o México e os Estados Unidos (41). E Derwent Whittlesey chega mesmo a acreditar na superioridade das fronteiras lineares sobre as fronteiras naturais, pois que aquelas

\footnotetext{
"expressam uma idéia mais compreensivel e mais conveniente ao povo" (42)
}

do que estas. E assim por diante.

Um estudo mais detalhado a respeito da função de alguns dos já referidos fatores geográficos será suficiente para mostrar e demonstrar que a teoria da fronteira natural, posto que nascida na Europa, não teve, praticamente, aplicação na sua história. Comecemos com o mar. Este, pelo alimento que oferece e pelo caminho que traça, não só atrai como une os homens (43) e entre a Ásia e a Europa ele ja-

océanes ni les fossés fluviaux ni les géants de la Montagne n'offrent d'insurmontables obstacles à l'éffort de la civilisation, "dompteuse d'espace". Cette épithète, que Ratzel propose à l'activité guerrière, s'appliquerait tout autant aux pacifiques victoires. En revanche, devant d'autres difficultés l'homme s'est toujours arrêté pile: fcrêts trop denses, marécages trop boueux, désert trop arides, qui refoulent, des deux parts, les peuples". (Op. cit., p. 90).

(39). - Op. cit., II, p. 122.

(40). - Idem, p. 121 .

(41). - Idem, p. 121-2.

(42). - Geografia Politica, México-Buenos Aires, Fondo de Culturä Económica, 1948, tradução de Júlio Le Riverend, p. 17.

(43). - Ancel, op, cit., p. 81. 
mais foi a fronteira, pois que esta deve ser encontrada alem, nas estepes, nos desertos anatólicos (44). O Mediterrâneo separando os homens? Nunca, sempre os ligou. Não foi ele que possibilitou à história dos fenícios não se desenvolver apenas numa pequena região do litoral da Ásia Menor, e sim se extender na sua parte oriental, e inclusive na sua parte ocidental onde, ao lado de dezenas de estabelecimentos púnicos, pontificou Cartago? E não foi através dele que a história dos gregos deixou de ser uma história da Grécia, para ser a história das poleis gregas espalhadas pelo Mediterrâneo, graças ao prodigioso acontecimento da colonização, fazendo com que a chamada comunidade panhelểnica adquirisse um carater mediterrâneo e não apenas grego, geograficamente falando? E não foi por intermédio dele que Roma impôs uma comunidade de civilização e de interesses, muito mais ampla e sólida do que a comunidade panhelênica, comunidade essa que é vista como o símbolo histórico mais legitimamente representativo do Mundo Antigo? O mar, portanto, não separa.

Alem disso, não defende, não protege. A Inglaterra, país essencialmente formado por fronteiras naturais marítimas, uma ilha, não encontrou no mar a sua tão apregoada inviolabilidade. César desembarcou nela, embora não pretendesse conquista-la (45); Cláudio invadiu-a e anexou-a ao Império Romano; anglos, saxões, jutas tambem invadiram-na; o Cristianismo nela penetrou; os escandinavos assaltaram-na e, em grande parte, conquistaram-na; finalmente, e sempre atraves do mar, Guilherme da Normandia dela se assenhoreou em 1066, encerrando o ciclo das invasões provenientes do continente que a Inglaterra conheceu na sua história. Aliás, foi pensando mais na história inglesa que Febvre acreditava que toda fronteira natural pode ser violada (46). Tanto isto é verdade - e os ingleses compreenderam-na melhor do que ninguem - que somente na medida em que a Inglaterra desenvolvia o seu poderio marítimo é que ela ia alcançando o seu esplêndido isolamento, ou seja, a sua segurança.

(44). - Idem, ibidem, p. 82.

(45). - E temerário acreditar-se que foi o mar, uma fronteira natural, que impossibilitou a conquista da Inglaterra por César. Este, na realidade, não cogitava de conquista-la. Jérôme Carcopino, interpretando os projetos de César referentes à Inglaterra e à Germânia, externa a seguinte opinião: "César les a conçus et exécutés. non pour conquérir la Bretagne ou la Germanie, mais pour affirmer son autonomie, assouplir les Gaules à son commandement, et tout ensemble étonner le monde romain, et, de longue main, en préparer la su* jétion". (César, Paris, Presses Universitaires de France, 1943, 3a. edição, p. 790-1).

(46). - Op. cit., p. 410. 
A montanha, alem de se revelar ineficiente como barreira às relações humanas (47), tambem por si só não garante a defesa (48). Os Pirineus, por exemplo, apesar de frequentemente considerados como fronteira perfeita, na realidade são ocupados por rebanhos de ambos os lados da cordilheira por ocasião do verão e, desde tempos imemoriais, os habitantes da zona desfrutaram dos pastos comuns, celebrando inúmeros tratados para esse fim (49). Os Alpes jamais se constituiram num obstáculo a impedir os desígnios humanos (50).

(47). - Colocando a montanha ao lado do rio como barreiras ineficientes, assim escreve Moodie: "São estes, apenas, alguns dos problemas inerentes ao uso de característicos físicos como limites políticos. Em parte alguma constituem eles linhas divisórias completas e contínuas. A única vantagem aparente no seu uso é que podem ser distinguidos na paisagem, sendo geralmente muito conhecidos pelos habitantes da fronteira". (Geografia e Política, Rio de Janeiro, Zahar Editores, 1965, tradução de Monteiro Oiticica, p. 109).

(48) . - "... there is the example of India, which in the years since independence has neglected her apparently secure Himalayan border in order to concentrate upon the development of the remainder of the country and the security of her Pakistan border". (J. R. V. Prescott, The Geography of Frontiers and Boundaries, Londres, Hutchinson University Library, 1965, p. 103).

(49). - Whittlesey, op . cit.. p. 17. A esse respeito assim, e respectivamente se pronunciam Febre e Ancel: "El mismo autor que citamos - refere-se a Calmette - , un historiador poco familizarizado con las cosas de la Geografía, plantea la cuestión en estos términos: "Si alguna frontera humana ha podido ser inmutable a través de los pocos siglos de nuestra breve historia nacional ?no parece que los Pirineos han debido serlo? Pues nada de eso. Ha habido, al contrario, una historia de la frontera de los Pirineos compleja, movida...". A decir verdad no nos sorprende. ?No hemos tenido anteriormente ocasión de hablar, con Cavaillès y Max Sorre, de estas federaciones pirenaicas que unen, que enlazan por medio de tratados los valles situados a una y otra parte de la cadena?. ?No hemos señalado el poder y la continuidad de esta marea regular y rítmica de la trashumancia que no respeta precisamente nuestros prejuicios de campeones inconscientes de las "fronteras naturales"?". (Op. cit., p. 402-3); "La masse pyrénéenne, que d'aucuns estiment "ffrontière morte" depuis 1659 , ne mourut jamais que estratégment. Les Pyrénées ont toujours offert dans leurs hauts valleé des "estives" pastorales, en exploitation communale, des associations ou "jurandes", qui signaient "traités de lies et de passeries" et ne tinrent jamais compte du tracé de la frontière. Sur leurs plateaux orientaux, les hautes valées pyrénéennes enserrent plus de paysans que les basses et les moyennes vallées, encaissées dans d'étroites gorges, comme celle de l'Aude. Les contacts fréquents, les passages aisés se souciaient peu des frontières". (Op. cit.; p. 88-9).

(50). - "Une imposante Montagne paraît le type même de la "frontière naturelle". Vauban se méfiait pourtant de cette terminologie facile et fallacieuse. Les Alpes, chaîne élevée, rébarbative, glaciaire, sont cependant occupées dès les âges préhistoriques: haches et fibules de bronze furent découvertes à 2. 340 mètres, et de l'arsenal de Hallstatt, dans l'Autriche salzbourgeoise, sortit la grande epée celte qui conquit l'Europe occidentale. Des voies romaines empruntèrent le Brenner, le col de Resia (Reschen), le Splügen, le Saint-Bernard. Les Slovènes, au VIe siècle, pénétrèrent à l'intérieur des Alpes jusqu'aux vallées internes, Pusteria (Pustertal) et Venosta (Vintschgau). Dès le VIIIe siècle, les Germains furent les défricheurs, les évangélisateurs, partis de l'archevêché de 
E o que evidencia a História. Costuma-se acreditar que a Itália, unificada por Roma, se encontrava, em virtude da sua configuração natural e da sua situação geográfica, diante de três problemas fundamentais: o problema tirrênico, o problema adriático e o problema continental (51). Diante daqueles três problemas, qual deles deveria merecer a preferência quanto a sua solução?: aos

"nossos olhos de modernos, parece que o problema continental devesse, pela sua própria urgência, beneficiar-se de um direito de prioridade. Mas, que a teoria das fronteiras naturais, que nos é cara, não nos cause ilusão. Os romanos apenas tardiamente consideraram os Alpes como o limite geográfico necessário da Itália, e sempre atribuiram a essa concepção um valor tão somente relativo" (52).

E mais, como que provando que os Alpes não protegiam a Itália, o grande perigo que Roma conheceu na sua história, o perigo anibálico, chegou por meio daquela portentosa cadeia de montanhas, o que levou o célebre historiador italiano Ettore Pais a não aceitar a atravessia dos Alpes por Anibal como épico empreendimento e sim como um acontecimento relativamente normal, visto que, antes do famoso condottiero cartaginês, populações inteiras, e não apenas um exército, já tinham realizado tal atravessia (53).

Salzbourg, des nombreux cloîtres carinthiens. Les Alpes ne furent point un obstacle pour leur cognée bûcheronne: tandis qu'au Nord des colonies allemandes se fondent à Znaim (en tchèque Znojmo) (1226), à Budweiss (Budejovice) (1265) aux confins de la Bohême, au Sud de la chaîne se créent celles de Levant en Carinthie et de Villach (1220), a l'Est Raab et Sankt-Gotthard devant la plaine panonique (1183). Aujourd'hui tout instable encore est la limite des langues: L'Allemand a passé le Brenner jusque dans le Tirol annexé à l'Italie; le français a franchi les Saint-Bernard, s'est infiltré dans le Val d'Aoste. Longtemps la Savoie-Piémont-Sardaigne, "portier des Alpes", à cheval sur les deux versants, fut gardienne des défilés". ( $O p$. cit., p. 88).

(51). - Léon Homo, L'Italie primitive et les débuts de l'impérialisme romain, Paris, Editions Albin Michel, 1938, 2a. edição, p. 292-3.

(52). - Idem, ibidem, p. 293-4.

(53). - "Alcuni fra gli storici antichi, per colpire i lettori e per ignoranza dei luoghi, esagerarono forse la difficoltà de l'impresa compiuta da Annibale, mentre altri ben sapevano che le Alpi non erano sin d'allora del tutto deserte ed impervie, e che più volte erano state attraversate dagli eserciti dei Galli venuti in Italia con le mogli et $i$ figli. Popolazioni Celtiche vi avevaro anzi messa lor sede sovrapponendosi al più vetusto strato ligure". (Storia di Roma durante le Guerre Puniche, Roma, Casa Editrice "Optima", 1927, I, p. 210). Aliás, Napoleão chegou mesmo a afirmar: "Quant à la difficulté du passage des Alpes, elle a été exagéré; il n'y en avait aucune: les eléphants seuls ont pu lui donner de l'embarras". (Commentaires VI, p. 163). E um historiador recente acredita: "Ostacolo maggiore delle difficoltà del luogo e del clima fu certamente quello opposto dalla ostilità dei montanari, che cagionò le maggiori perdite di soldati e di animali da soma". (Giuglio Giannelli, Roma nell' Età delle Guerre Puniche, Bolonha, Licinio Cappelli Editore, 1938, p. 163) . 
Impossivel tambem acreditar-se no rio como uma fronteira natural em condições de obstar a ligação entre os homens e se constituir em fator geográfico capaz de proporcionar a segurança dos mesmos. Antes o contrário é que devemos acreditar. $\mathrm{E}$ a escolha do Reno, o mais famoso e tormentoso rio da história da humanidade, como objeto das nossas cogitações, será suficiente para o que pretendemos comprovar. Este rio, desde a aurora da história do homem até o desenvolvimento da civilização moderna, sempre apresentou sua grande originalidade, malgrado as paixões nacionais: sua virtude de ligação e de reaproximação na vida e na obra das sociedades humanas (54). Seu destino foi o de ser

\footnotetext{
"não uma barreira mas um caminho. Um vínculo, não um fosso" (55).
}

E exatamente por estar sempre destinado a ligar e nunca a separar é que o Reno jamais foi e pode ser considerado como eficiente elemento defensivo: afinal de contas, não se deve esquecer que as impropriamente chamadas invasões germânicas - responsabilizadas por alguem pelo fato da civilização romana não ter morrido da sua bela morte, porque foi por elas assassinada (56) - cujos inícios, convem frisar, se deram pela atravessia de um outro rio, o Danúbio, abateram-se sobre o Império Romano do Ocidente através do Reno (57). Tais foram as relações que ele proporcionou, e cada vez mais continua proporcionando, que jamais o Reno foi uma barreira. Aparece como fronteira apenas nos atlas (58). Havendo mesmo quem, ao estabelecer diferença entre fronteiras e limites - aquelas, relacionando-se

(54). - Albert Demangeon e Lucien Febvre, Le Rhin, problèmes d'histoire et d'économie, Paris, Librairie Armand Colin, 1935, p. 291.

(55). - Idem, ibidem, p. 11.

(56). - André Piganiol, L'Empire Chrétien (325-395), Paris, Presses Universitaires de France, 1947, p. 422.

(57). - "Encore est-il vrai qu'en temps où son lit ne se ressemblait en rien au chenal approfondi et partout pourvu de rives artificielles que nous connaissons, l'hiver et ses gelées, l'été et ses secheresses offraient des possibilités qui souvent devaient inquiéter les Romains. Il le faut, puisqu'en l'absence de ponts, mais non de gués, des tribus entières avec femmes, enfants, bagages et ces énormes chariots qui, le soir, servaient à retrancher les camps des migrateurs, n'ont cessé en fait de passer le Rhin. Transire Rhenum, les deux mots reviennent à combien de pages des Commentaires? Et du Rhin au lit assez fixe pour servire de frontière (qui terminus esse sufficiat) - Tacite, dans sa Germania (32), ne distingue-t-il pas le Rhin impropre à créer une limite? - Ailleurs, dans les Histoires (LV, 126), ne nous montre-t-il pas les légions contraintes d'établir des postes sur les berges pour empêcher les Barbares de passer à gué un fleuve incapable de porter bateau: dispositae per omnem ripam stationes, quae Germanos vado arcerent?" (Demangeon e Febvre, op. cit., p. 13). 
com áreas, porque fazem parte da superfície da Terra podem ser, corretamente, denominadas "naturais"; estes, lineares pela sua natureza, quando selecionados, definidos e demarcados pelo homem, quer em conformidade ou não com os característicos físicos do terreno, são artificiais - chegue a afirmar que:

"Em virtude dessa diferença, é muito justo considerar, por exemplo, o solo do vale do Reno como "fronteira natural" entre a Alemanha e a França, porem a escolha e o uso do rio Reno como parte do limite franco-alemão emprestam a essa linha carater artificial; embora o rio seja "natural", isto é, característica física, seu uso como limite político é artificial" (59).

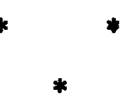

Se dermos, a partir de agora, um tratamento mais especificamente histórico à questão da fronteira natural, sem muita dificuldade, mediante novos exemplos alem dos já citados, chegaremos à conclusão de que a história européia muito mais rejeitou do que aceitou a teoria da fronteira natural. A história de Roma é, praticamente, a rejeição da teoria de que desde

"a mais remota Antiguidade os rios alternam com as cadeias de montanhas para fornecer aos Estados limites naturais"

e que quem diz limite natural

"diz limite predestinado - ideal a conquistar e a realizar".

Já vimos como Roma apenas tardiamente se preocupou com os Alpes como fronteira geográfica necessária à Itália. Como já vimos tambem o desembarque de César na Inglaterra e a posterior conquista da ilha no tempo de Cláudio. Exemplos típicos de política de negação da teoria da fronteira natural ou, para sermos mais precisos, política de fronteira "anti-natural". A esses exemplos, outros podem ser acrescentados, atestando a despreocupação romana em relação à fronteira natural. Em 225 a. C. embaixadores romanos celebravam com Asdrubal, genro de Amilcar Barca, e que vinha realizando grandes progressos na Espanha, tratado que estabelecia o rio Ebro como limite das conquistas cartaginesas. Era o famoso tratado do Ebro. Consi-

(58). - Ancel, op. cit., p. 85.

(59). - Moodie, op. cit., p. 84. 
derava Roma, com esse tratado, o rio Ebro como fronteira natural em condições de impedir um posterior avanço púnico? Evidentemente não, pois o mais lógico seria que se preferisse os Pirineus, indiscutivelmente uma barreira muito mais a ser considerada do que o estreito rio. Aliás, um historiador chega mesmo a perguntar:

"Por que o Ebro, e não os Pirineus?", para em seguida, convincentemente responder: "Certamente, para salvar as colônias massaliotas de Empória e de Rodes; mas tambem, e sobretudo, para impedir o estabelecimento da contiguidade territorial do império cartaginês da Espanha com os paises gálicos" $(60)$.

O que importava a Roma, assim, era o impedimento da contiguidade galo-cartaginesa e, para tanto, os Pirineus facilitavam-na, ao invez de dificulta-la ou impedi-la. E a conquista da Gália Transalpina por Cesar tambem não foi uma demonstração de que preocupações de ordem histórica superavam óbices de ordem geográfica, representados por uma fronteira natural, os Alpes? Poder-se-ia, é bem verdade, objetar: por que Roma não conquistou a Germânia, região localizada alem Reno? Por que Roma via no Reno, outra fronteira natural, um obstáculo que a obrigava a deter-se diante dele? Não, embora, entre outras, algumas razões de carater geográfico - mas nunca a fronteira natural - como que impossibilitavam a Roma a conquista da Germânia. E que os germanos se caracterizavam, nômades que eram, pela sua crônica mobilidade, vivendo do presente sem fazer reservas, e essa

"mobilidade crônica dos povos que habitavam as planícies setentrionais da Europa explica porque a Germânia escapou ao domínio de Roma",

pois o organismo político criado pelos romanos

"não fora feito para adaptar-se à uma comunidade movel" e a administração romana, "assentada sobre a propriedade territorial, supunha o sedentarismo das populações que ela anexava" (61).

(60). - Giannelli, op. cit.. p. 146.

(61). - Roger Dion, Influência da geografia física sobre a evolução histórica da Europa (As invasões bárbaras vistas pelo geógrafo), in "Revista de História", São Paulo, 1950, I, p. 135. Ainda deste famoso geógrafo francês sentimo-nos como que compelidos a transcrever o seguinte: "A instabilidade dos grupos humanos tornava a Germânia refratária, não somente ao estabelecimento da administração romana, mas, desde logo, à própria penetração dos exércitos 
Da mesma forma, Roma tambem não via na fronteira natural um elemento capaz de defende-la em relação aos seus inimigos. $\mathbf{O}$ limes, linha fortificada que se extendia gradualmente às diferentes fronteiras do Império (62), era quem na realidade se constituia na fronteira do mundo romano face aos povos que o ameaçavam. Mas o limes, convenhamos, não era uma fronteira natural, e sim uma fronteira militar (63).

Deixemos o mundo romano e pentremos um pouco na Idade Média que, aliás, com as invasões germânicas, se inicia pelo flagrante desrespeito às fronteiras naturais. Carlos Magno orientou sua política de conquistas e que acabou desfechando na formação do Império Carolíngio, no sentido das fronteiras naturais? Não, pois conquistou e anexou à monarquia franca, entre outras regiões, a Itália lombarda, situada alem Alpes e a marca da Espanha, situada alem Pirineus. Da divisão do Império Carolíngio, consagrada pelo tratado de Verdun de 843, constituiram-se alguns dos estados da Europa continental. Mas essa divisão não se fez respeitando-se considerações de ordem geográfica: tanto isso é verdade que a parte central, cortada pelos Alpes e pelo Jura, extendia-se da Itália até a Holanda

romanos. Cesar, sobre esse ponto, não pode ser mais claro. Escreve (VI, 29, I) : "... receioso de carência de provisões, sendo que mui pouco se dão os germanos à agricultura, como se disse, resolve Cesar não avançar mais,...".

Pode-se ver o encadeamento das causas e dos efeitos: não sendo verdadeiros sedentários, os germanos não podiam cuidar da agricultura; não faziam reservas e viviam principalmente do gado que levavam consigo. Mas, os exércitos romanos em campanha não dispunham de meios de transporte que lhes permitisse trazer reabastecimento de muito longe. Viviam nas regiões que atravessavam, dos estoques de trigo e de feno, conservados nos centros agrícolas que encontravam pelo caminho. Seu reabastecimento tornava-se muito dificil, senão impossivel, numa região de agricultura rudimentar, onde as principais reservas consistiam em rebanhos que os fugitivos levavam consigo. A Germânia escapou assim ao domínio da Roma". (Op. cit., loc. cit., p. 135).

(62). - Homo, Le Haut-Empire, Paris, Presses Universitaires de France, 1941. p. 608 .

(63). - "L'Empire Romain a la réputation d'avoir souvent fixé ses frontières à des fleuves: le Rhin, le Danube... pourtant le limes romain était souvent établi en avant du fleuve frontalier. Les positions romaines ont débordé à l'Est du Rhin en Allemagne, au Nord du Danube en Roumanie par exemple, au Nord de la Tyne en Nerthumberland. Le fleuve semblait être plutôt une position commode de repli derrière les positions avancées de l'Empire: et, tant que le territoire impérial n'était pas là menacé, le fleuve était une excellente route, animant la vie économique de la province, facilitant les communications civiles comme militaires à l'arrière immm ́diat de la frontière". (Jean Gottmann, La Politique des Etats et leur Géographie, Paris, Librairie Armand Colin, 1952, p. 122. 
"sem levar em conta as fronteiras naturais nem a natureza dos povos" (64).

Tambem na Idade Moderna não há muito que se levar em conta a fronteira natural como fator determinante da política européia. Vejamos, para tanto, a política externa da França durante o chamado Antigo Regime que, em grande parte, mas erroneamente, se pretendeu explica-la em função da fronteira natural. Embora seja banal verdade que a formação territorial da França foi obra da monarquia, é impossivel aceitar-se que a contribuição de cada monarca na construção do edifício territorial francês seguiu um plano de conjunto ou que seus esforços foram guiados por alguma idéia diretora (65). Eis porque, assim como não se deve aceitar a teoria das fronteiras linguísticas como caucionante das empresas de expansão francesa sob o Antigo Regime, tambem não se pode aceitar a teoria segundo a qual os monarcas franceses

"se teriam proposto dar à França suas fronteiras "naturais": Alpes, Reno e Pirineus" (66).

Gaston Zeller, autoridade reputada na política externa do Antigo Regime, informa-nos que, pouco antes da eclosão da Segunda Guerra Mundial, foi instituida uma comissão de historiadores franceses e alemães com a finalidade de expurgar dos manuais escolares afirmações tendenciosas, capazes de prejudicar o bom entendimento entre os povos, e que ela, categoricamente, se pronunciou contra a interpretação da política monárquica baseada na teoria da fronteira natural, teoria à qual o público se ligou por razões de ordem puramente passional (67). A referida comissão relacionou as seguintes principais razões contrariamente à teoria da fronteira natural: durante os três últimos séculos da monarquia francesa, somente dentre uma meia dúzia de publ:cistas, isto é, de indivíduos sem responsabilidade em relação aos negócios públicos, aparece a idéia das fronteiras naturais, ou mais especificamente, a idéia do Reno fronteira; os homens de Estado dela não

(64). - Henri Pirenne, Histoire de l'Europe des invasions au XVIe siècle. B. uxelas, Nouvelle Société d'Éditions, 1936, 6a. ediç̃o, p. 76.

(65). - Gaston Zeller, La politique extérieure de l'Ancien Régime, in "L'Info. mation Historique", Paris, 1938, n' 1, p. 15.

(66). - Idem, ibidem, p. 15. Referindo-se à teoria da fronteira natual assim se manifesta o mesmo autor: "Telle théorie à succès lancée à l'époque romantique, en un temys où l'histoire ne s'était pas encore imposé des mśthodes scientifiques, a brouillé la vie de plusieurs générations. Et, aujoud'hui encore, on ne sau:ait dire qu'elle ait cessé d'être gêrante". (Loc. cit., p. 15).

(67). - Idem, ibidcm, p. 15. 
fizeram uso, mesmo porque, alguma frase célebre atribuida a Richelieu -

"A finalidade do meu ministério foi a de restituir à Gália as fronteiras que a natureza thes fixou..."

- pertence a um documento apócrifo e cuja autenticidade jamais alguem, seriamente, defendeu; foi uma idéia estranha ao espírito do Antigo Regime, como demonstra, sintomaticamente, o entusiasmo que ela ocasionou entre os homens do ano I da Revolução Francesa que a incorporaram ao credo republicano, já que ela oferecia à nova França, a França revolucionária, um quadro racional e inédito ao mesmo tempo (68) . Na realidade, a política externa do Antigo Regime variou conforme os homens $\mathrm{e}$ as circunstâncias. E assim que Carlos VIII inaugura uma política de aventuras italianas, o que quer dizer alem das fronteiras naturais da França, política essa que durou meio século, mas que de um só golpe se dissipou sob as ameaças originárias nos progressos da Reforma protestante (69). Se bem que no pensamento dos homens que concluiram o tratado de Cateau-Camb:ésis (1559),

"a renúncia aos territórios transalpinos não era senão provisória",

os acontecimentos acabaram por torna-la definitiva. Para poder retomar o caminho da Itália era necessário um triunfo rápido e completo sobre a heresia: isto, porem, foi impossivel, pois o periodo das guerras civis se prolongou durante quase quarenta anos e ele terminou por um compromisso que deixava o reino perigosamente dividido em relação a si próprio (70). Dessa forma, é a conclusão que se impõe, não fossem as guerras civis da questão religiosa, e a França persistiria vinculada a uma política, a italiana, que era exatamente a política oposta a das fronteiras naturais.

No bojo das guerras de religiẫo surge Richelieu,

(68). - Idem, ibidem, p. 15. Confira-se ainda do mesmo autor: La Mona chie d'Ancien Régime et les frontières naturelles, in "Revue d'histoire moderne", 1933; Histoile d'une idée fausse, in "Revue de synthèse", tomo XI, 1936. p. 16 .

(69) - - Zaller, La politique extérieure de l'Ancien Régime, loc. cit., (70). - Idem, ibidem, p. 16. 
"por muito tempo representado como o campeão por excelência das fronteiras naturais" (71).

Richelieu foi um campeão sim, mas de uma política que visava unir todos os adversários da Casa da Âustria, fossem eles católicos ou protestantes, a fim de, com essa união, evitar os perigos inerentes aos progressos dos Habsburgos (72). Queria frear os avanços da Espanha, e evitar que a Áustria, num Anschluss às avessas (73), absorvesse a Alemanha, escapando dessa forma à ameaça de cerco que pesava sobre a França. Nada disso estava relacionado com uma política defensiva baseada nas fronteiras naturais. Se assim não fosse, como explicar o fato de Richelieu não ter aceito em 1632 proposta de Gustavo Adolfo que lhe facultava obter a margem esquerda do Reno, desde que aderisse à política do monarca sueco de conquistas na Alemanha onde ele, indubitavelmente, visava estabelecer um império protestante? E que a vantagem, a fronteira natural, de muito era inferior ao altíssimo preço que deveria pagar por ela, ou seja, a unidade da Alemanha (74). Unidade esta que a França, bem o sabemos, e porque, sempre procurou evitar... Aliás, para Richelieu, a fronteira ideal não era aquela que devia colocar a França ao abrigo da invasão e sim, e sobretudo, a que the permitisse levar as armas francesas para fora (75): daí se compreender porque - palavras textuais suas no célebre Avis au Roi de 1629 -

(71). - Idem, ibidem, p. 17. A respeito de Richelieu e as fronteiras naturais ainda observa Zeller em uma outra de suas obras: "A peine est-il besoin de mentionner ici la thèse périmée qui fait de Richelieu un champion des frontières naturelles. Il est bien dtmontré que la politique des frontières naturelles, pour lesquelles les Français de 1792 devaient s'enthousiasmer, a été arbitrairement antidatée. L'erreur remonte d'ailleurs au XVIIe siècle. C'est l'auteur d'un Testament politique du cardinal, oeuvre apocryphe parue peu après sa mort, qui a le premier prétendu que Richelieu avait eu l'ambition de "borner la France par le Rhin". - Rappelons, pour éviter tout malentendu, qu'il existe un autre écrit, authentique celui-là, appelé Testament politique de Richelieu, et d'autre part que Strasbourg, ville libre, ville d'Empire, se trouve, à cette époque, au point de vue politique, en marge de l'Alsace". (De Chistophe Colomb d Cromwell, in Histoire des Relations Internationales, direção de P. Renouvin, Paris, Librairie Hachette, 1953, tomo II, p. 242, in nota. Para tornar compreensivel o final da citação de Zeller, acreditamos dever esclarecer que Richelieu se interessava por Estrasburgo, mas não se interessava pela Alsácia.

(72). - Zeller, De Christophe Colomb à Cromwell, p. 239.

(73). - Léon Abensour, Richelieu, in "L'Information Historique", Paris, 1939, n० 4, p. 164.

(74). - Idem, ibidem, p. 164.

(75). - Zeller, La politique des frontières au temps de la préponderance espagnole, in "Revue Historique", Paris, 1942-3, tomo 193, p. 110. 


\begin{abstract}
"se devia avançar até Estrasburgo, caso possivel, para obter-se uma entrada na Alemanha" (76);
\end{abstract}

e porque solidamente se assenhoreou de certas regiōes alpinas, a fim de, mais facilmente, penetrar na Itália. Tudo isso para que a França, conforme a uma tradição já antiga de protetora de pequenos estados na Alemanha e na Itália, devesse estar sempre em condições de responder-lhes ao apelo que eles poderiam dirigir-lhe contra os Habsburgos (77). E por fim, Richelieu entra na guerra. Evidentemente que não na qualidade de campeão das fronteiras naturais. Eis aí um título que jamais deveria ser-lhe atribuido; mesmo porque nunca pretendeu conquista-lo!

Em vão, caso proseguissemos na análise da política externa do Antigo Regime, esforçar-nos-iamos tentanto encontrar a aplicação da teoria da fronteira natural. A política de Luis XIV, por exemplo, só teve um objetivo, a glória pessoal; e os monarcas do século XVIII renunciaram à política de prestígio.

Todavia, por ocasião da Revolução Francesa, mais precisamente a partir de 1792, ressurge a teoria da fronteira natural com vigor nunca visto até então. Era assim que proclamavam os revolucionários:

"Seus limites - refere-se aos da França - são marcados pela natureza. Nós os atingiremos todos nos quatro cantos do horizonte, do lado do Reno, do lado do Oceano, do lado dos Alpes" (Danton); "Os limites antigos e naturais da França são o Reno, os Alpes e os Pirineus" (Carnot); "A própria Natureza quiz que o Reno fosse a fronteira da França. Efetivamente ele o era nos primeiros séculos do reino da França" (Forster).

O certo é que nos fins de 1792 e inícios de 1793 a Convenção votou a anexação à França de regiōes como a Savóia, o condado de Nice, a Bélgica e a margem esquerda do Reno. Mas essas anexações não foram determinadas pela teoria da fronteira natural. Apesar das proclamações revolucionárias acima citadas, a teoria foi empregada tão somente para justificar as referidas anexações. Contudo, por que se fizeram tais anexações, algumas das quais, caso mais precisamente da Bélgica, levaram a Europa a se coligar contra a França revolucionária? Em primeiro lugar, as conveniências da política interna aconselhavam aos girondinos não se deixarem ultrapassar no zelo revo-

(76). - Apud idem. ihidem. p. 105.

(77). - Zeller, De Christophe Colomb à Cromwell, p. 241. 
lucionário (78). E em segundo lugar, porque os revolucionários concluiram que era preciso anexar os povos daquelas regiōes a fim de impedir que eles se passassem para a contra-revolução (79). Alem disso, convem não esquecer que as guerras da Revolução acabaram ultrapassando de muito as fronteiras naturais da França, chegando por fim a adquirir âmbito mundial se considerarmos que Napoleão não passou de um herdeiro e continuador delas.

E, para encerrar, podemos explicar a rivalidade franco-alemã no decorrer do século XIX, mais precisamente, a disputa pela posse do Reno, motivada pela fronteira natural? Novamente somos obrigados a dizer que não. Não se pretendia o rio porque ele era uma fronteira. Pretendia-se sim o domínio de um rio que era a saida de uma via colossal de tráfego e de influência, atingindo pelo São Gotardo e Gênova - Mediterrâneo, e atingindo, pelo Danúbio e Istambul, a Ásia anterior, Bagdá, golfo Pérsico, que era, enfim, o traço de união entre o mar do Norte e os mares asiáticos (80). Questão de fronteira, de fronteira natural? Absolutamente não. Questão de interesse político e econômico? Absolutamente sim.

Acreditamos agora estar em condições de concluir que a teoria da fronteira natural não teve força suficiente para determinar fatos na evolução histórica européia. Nenhum chefe de Estado, nenhum povo empenhou suas potencialidades para, através delas, dotar seus respectivos paises de fronteiras naturais, objetivando com isso nada mais que a materialização de uma teoria. E note-se que as ambições de ordem territorial sempre estiveram presentes na história da Europa. Não porem condicionadas pela teoria da fronteira natural. Aliás, os geógrafos tem opinião formada a respeito: Moodie acha que as fronteiras naturais apenas devem ser tomadas como pretexto ou justificativas de tais ambições, servindo tão somente para disfarce das atividades expansionistas, mormente nas regiões em que os característicos físicos oferecem vantagens estratégicas ou econômicas (81); e Max Sorre ve nelas não mais que o alimento das controvérsias dos diplomatas (82).

(78). - André Fugier, La Révolution Française et PEmpire Napoléonien, in Histoire des Relations Internationales, direção de P. Renouvin, Paris, 1954, Librairie Hachette, IV, p. 70.

(79). - G. Lefebvre, La Revolución Francesa y el Imperio, México, Fondo de Cultura Económica, 1960, tradução de Ma. Teresa de Salazar, p. 98.

(80). - Demangeon e Febvre, op. cit., p. 147.

(81). - Op. cit., p. 110.

(82). - Op. cit., II, p. 122. 
Lamentavelmente, no entanto, não é essa opinião formada pela maioria dos nossos historiadores. Vimo-los apossarem-se de uma teoria européia, mas inaceitavel na própria história da Europa, transporta-la para a história do Brasil e, confundindo o acessório com o essencial, a justificativa - se de fato houve - com o determinante, usar e abusar dela para, "candidamente", explicar a conquista da Cisplatina por D. João VI. Porque não concordamos e nem podemos concordar com essa maneira de se explicar tal conquista, ou seja, determinada pelo atrativo da fronteira natural, no caso o rio da Prata, é que, oportunamente, preocupar-nos-emos com a questão. 